\title{
BEHAVIOR OF HIGH STRENGTH CFSST STUB COLUMNS WITH INNER CFRP TUBE UNDER AXIAL COMPRESSIVE LOAD
}

\author{
Guochang $\mathrm{Li}^{1, *}$, Yan Lang ${ }^{2}$ and Zhijian Yang ${ }^{3}$ \\ ${ }^{1}$ School of Civil Engineering, Shenyang Jianzhu University, Shenyang, 110168, China \\ ${ }^{2}$ Department of Building Engineering, Suqian College, Jiangsu Province, 223800, China \\ ${ }^{3}$ School of Civil Engineering, Tianjin University, Tianjin, 300072, China \\ *(Corresponding author: E-mail: cegcli@sjzu.edu.cn)
}

Received: 9 September 2010; Revised: 10 December 2010; Accepted: 13 December 2010

\begin{abstract}
The contribution of CFRP (carbon fiber-reinforced polymer) to concrete-filled square steel tube (CFSST) is considered in this paper. Based on the experimental study of six high strength concrete-filled square steel tubular stub columns with inner CFRP circular tube (HCFSST-CFRP), the finite element software ABAQUS is employed to analyze the mechanical behaviors of HCFSST-CFRP stub column under axial compression load. Mechanism of interactions among steel tube, concrete core (includes two parts: innermost concrete and sandwich concrete) and CFRP is analyzed, and a simplified equation of loads shared by innermost concrete and sandwich concrete is given by regression analysis. Longitudinal stress distribution in the concrete section, load shared coefficient and axial load-strain relationships are presented. The confinement effect of the CFRP tube increases ductility of HCFSST stub columns remarkably. Innermost concrete suffers most of axial load after specimen reaching ultimate bearing capacity because of the confinement effect of CFRP tube. CFRP tube begins to work obviously at the descent stage after stub column reached ultimate bearing capacity.
\end{abstract}

Keywords: CFRP, Concrete-Filled square steel tube, Finite element, Test, Ultimate bearing capacity

\section{INTRODUCTION}

In recent years, with the development of steel and concrete composite structures, composite structures have attracted considerable attention. Because of the widely use of concrete-filled steel tube (CFST) structure, lots of research have been done by Schneider, Bridge, Han and others [1-5]. CFST members generally are divided into two types: square and circular. Zhong [6] presented that CFST has superior performance, like ductility and ultimate bearing capacity, compared with concrete-filled square steel tube (CFSST). However, CFSST structures have been used in some high-rise building in recently years [7-9]. Many solutions were presented to improve the performance of CFSST column, such as concrete-filled tube columns with confinement effect presented by $\mathrm{Hu}$ [10], CFSST columns with binding bars presented by Cai [11], composite-sectioned square concrete-filled steel tubes presented by Wang [12], concrete-filled square steel tubular columns reinforced by inner circular steel tube presented by Lu [13], and FRP-confined concrete-filled steel tubes presented by Tao [14]. Exploration and innovation of new material and structures is pushing the development of composite structures greatly. The research on application of carbon fiber material in CFST structures has become a popular issue.

On account of excellent mechanical properties of carbon fiber-reinforced polymer, a new type of composite column is proposed, which is constituted by inner CFRP tube, square steel tube and concrete core (includes two parts: innermost concrete and sandwich concrete) infilled. The test of six high strength concrete-filled square steel tubular stub columns with inner CFRP circular tube (HCFSST-CFRP) were conducted in this paper. 


\section{TEST}

\subsection{Specimen Preparation}

Cold-formed square tube was used in the test. Width to thickness ratios range from 33 to 55 , and thickness of CFRP tube ranges from 0.334 to 0.668 (thickness of adhesive excluded). The cross-section properties of specimens are listed in Table 1. The specimen number (for example: AS42) in Table 1 is labeled as follows: A stands for axial compression load; S stands for stub column; The first number stands for the thickness of steel tube, which means $3.5 \mathrm{~mm}, 4.5 \mathrm{~mm}$ and $5.8 \mathrm{~mm}$ respectively; The second number stands for the layers of CFRP which is two or four layers. $B$ is cross section height of square steel tube; $t$ is the thickness of square steel tube; $L$ is the length of specimen; $\alpha$ is steel ratio, expressed as $\alpha=A_{\mathrm{s}} / A_{\mathrm{c}}$, where $A_{\mathrm{s}}$ is steel cross-sectional area and $A_{\mathrm{c}}$ is concrete cross-sectional area; $\beta$ is carbon fiber ratio, expressed as $\beta=A_{\mathrm{f}} / A_{\mathrm{c}}$, where $A_{\mathrm{f}}$ is CFRP cross-sectional area; $\xi_{\mathrm{s}}$ is steel confinement factor, expressed as $\xi_{\mathrm{s}}=\alpha\left(f_{\mathrm{y}} / f_{\mathrm{ck}}\right)$, where $f_{\mathrm{y}}$ is yield strength of steel and $f_{\text {ck }}$ is characteristic concrete strength $\left(=0.4 f_{\mathrm{cu}}{ }^{7 / 6}\right.$ presented by Yu [15], where $f_{\text {cu }}$ is cubic compressive strength). $\xi_{\mathrm{f}}$ is CFRP confinement factor, expressed as $\xi_{\mathrm{f}}=\beta\left(f_{\mathrm{f}} / f_{\text {ck }}\right)$, where $f_{\mathrm{f}}$ is the tensile strength of CFRP. $N_{\text {ue }}$ is experimental ultimate bearing capacity of test. $N_{\text {be }}$ is experimental bearing capacity when CFRP ruptures.

Unidirectional carbon fiber sheets (CFS) were manufactured by Toray Industries in Japan, with weight is $300 \mathrm{~g} / \mathrm{m}^{2}$ and width is $500 \mathrm{~mm}$. PVC tube with diameter of $125 \mathrm{~mm}$ was used as mold. JGN-C adhesive manufactured by Liaoning Building Science Research Institute was used. The preparation process of the CFRP tube is shown as follows: Firstly, unidirectional carbon fiber sheet was cut into pieces as designed. Secondly, plastic membrane was wrapped around PVC tube in order to demount CFRP tube more easily. Thirdly, carbon fiber pieces were pasted around mold PVC tube with fibers oriented in the lateral direction of the PVC tube. Meanwhile gas bubbles between carbon fiber layers should be excluded in time. After air-drying for 4 hours, another carbon fiber piece was pasted over the former layer, as shown in Figure 1(a). The surface of the fabricated CFRP tube is too uneven to measure the thickness. So the thickness of adhesive wasn't considered in the fabricated CFRP tube.

Table 1. Specimen Schedules

\begin{tabular}{ccccccccc}
\hline No. & Specimen & $B \times t$ & $L$ & $\alpha$ & $\beta$ & $\xi_{\mathrm{s}}$ & $\xi_{\mathrm{f}}$ & $N_{\mathrm{ue}}\left(N_{\mathrm{be}}\right)$ \\
\hline 1 & AS42 & $200 \mathrm{~mm} \times 4 \mathrm{~mm}$ & $600 \mathrm{~mm}$ & 0.0739 & 0.0107 & 0.369 & 0.748 & $3044 \mathrm{kN}(3089 \mathrm{kN})$ \\
2 & AS44 & $200 \mathrm{~mm} \times 4 \mathrm{~mm}$ & $600 \mathrm{~mm}$ & 0.0739 & 0.0215 & 0.369 & 1.5 & $3259 \mathrm{kN}(3484 \mathrm{kN})$ \\
3 & AS52 & $200 \mathrm{~mm} \times 5 \mathrm{~mm}$ & $600 \mathrm{~mm}$ & 0.0965 & 0.0107 & 0.458 & 0.748 & $3274 \mathrm{kN}(3302 \mathrm{kN})$ \\
4 & AS54 & $200 \mathrm{~mm} \times 5 \mathrm{~mm}$ & $600 \mathrm{~mm}$ & 0.0965 & 0.0215 & 0.458 & 1.5 & $3299 \mathrm{kN}(3875 \mathrm{kN})$ \\
5 & AS62 & $200 \mathrm{~mm} \times 6 \mathrm{~mm}$ & $600 \mathrm{~mm}$ & 0.1269 & 0.0107 & 0.689 & 0.748 & $3725 \mathrm{kN}(3694 \mathrm{kN})$ \\
6 & AS64 & $200 \mathrm{~mm} \times 6 \mathrm{~mm}$ & $600 \mathrm{~mm}$ & 0.1269 & 0.0215 & 0.689 & 1.5 & $3755 \mathrm{kN}(4592 \mathrm{kN})$ \\
\hline
\end{tabular}

With simple galvanized iron frame, the fabricated CFRP tube was fixed in the centre of the square steel tube, as shown in Figure 1(b). All the specimens were cast with one batch of ready-mixed and self-compacting concrete of designed strength of C60. After concrete curing for two weeks, angle grinding machine with diamond cutter was used to grind concrete and CFRP which were higher than the top cross-section of steel tube. This was to ensure that the load was applied evenly on the cross-section of specimen and simultaneously to the steel and concrete. Properties of steel, concrete and CFRP are shown in Table 2. 


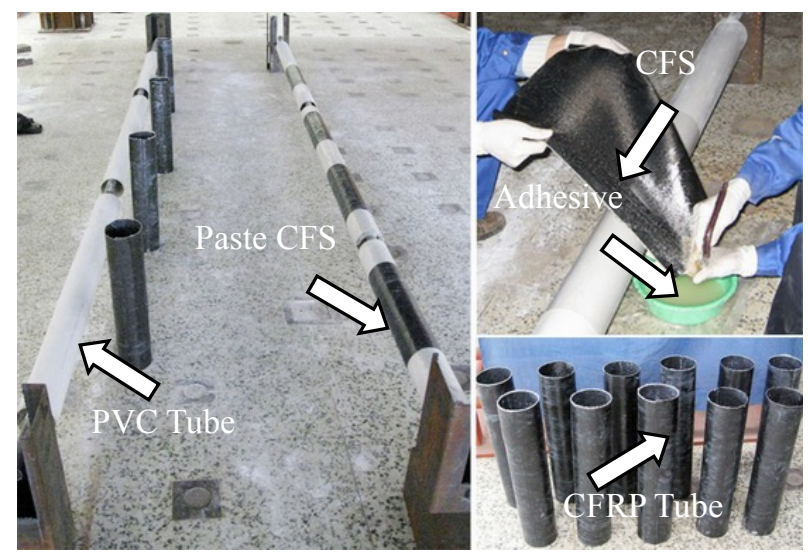

(a) The Fabrication of CFRP Tube

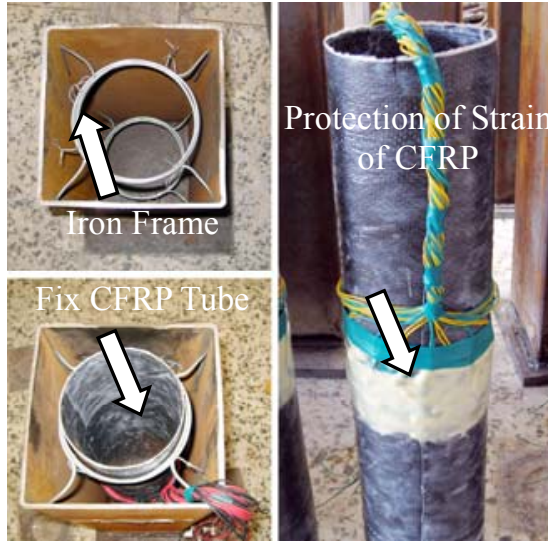

(b) Assembly View

Figure 1. The Fabrication of Specimen

Table 2. Material Properties

\begin{tabular}{ccccc}
\hline Material (grade) & $\begin{array}{c}\text { Yield } \\
\text { strength }\end{array}$ & $\begin{array}{c}\text { Tensile strength } \\
\text { (Cubic Compressive } \\
\text { strength) }\end{array}$ & $\begin{array}{c}\text { Elastic } \\
\text { modulus }\end{array}$ & $\begin{array}{c}\text { Poisson's } \\
\text { ratio }\end{array}$ \\
\hline Steel (Q235) & $291 \mathrm{MPa}$ & $418 \mathrm{MPa}$ & $201 \mathrm{GPa}$ & 0.29 \\
Concrete (C60) & & $(62.7 \mathrm{MPa})$ & $38.1 \mathrm{GPa}$ & 0.184 \\
CFRP (T700-12k/300g) & & $3718 \mathrm{MPa}$ & $292 \mathrm{GPa}$ & 0.308 \\
\hline
\end{tabular}

\section{$2.2 \quad$ Testing Equipment}

All the tests were performed on a $5000 \mathrm{kN}$ capacity testing machine. Figure 2 gives a schematic view of the test arrangements. In order to measure exactly deformation of specimen, eight strain gauges were pasted on the surface of each steel tube, and sixteen strain gauges were pasted symmetrically around the CFRP tube. Two linear voltage displacement transducers (LVDTs) were used to measure the axial deformation, as shown in Figure 2.

Specimen and testing machine were adjusted and aligned to make sure that the cross groove on the plate of testing machine align with middle of plate of the specimen. Preload specimen according to load interval of less than 1/10 of the estimated ultimate bearing capacity until load achieved about $30 \%$ of the estimated ultimate bearing capacity. Grade loading pattern was applied in the test and each load interval was maintained for about $2-3 \mathrm{~min}$. The progress of deformation, the mode of failure, and the maximum load of the specimens were duly recorded. 


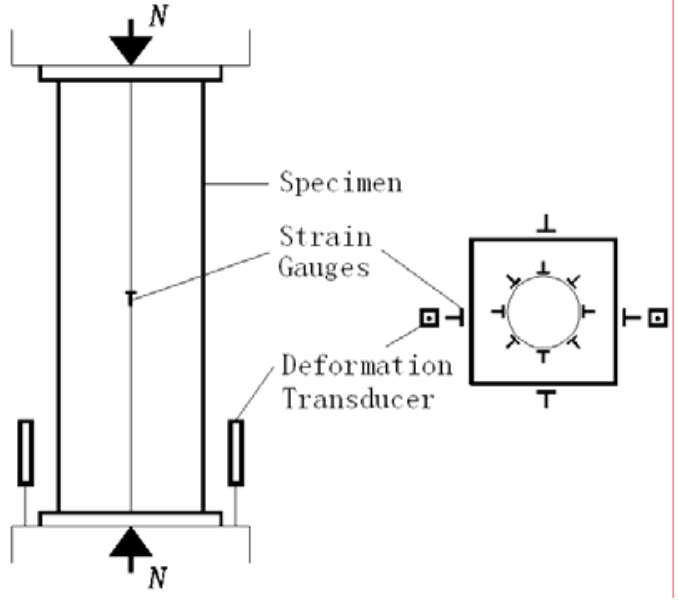

(a) Schematic View

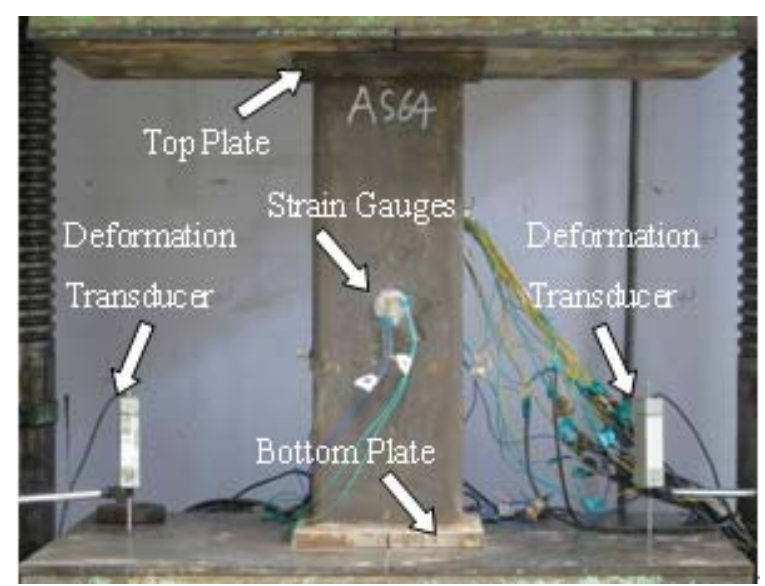

(b) Test View

Figure 2. View of the Test Setup

\section{$2.3 \quad$ Test Results}

In the progress of the test, deformation of specimen was not obvious, and bearing capacity $(N)$ was in linear relation with average axial strain $(\varepsilon)$ at preliminary stage of loading. When load attained $80 \% \sim 90 \%$ of ultimate bearing capacity, the growth rate of load apparently slowed. Meanwhile continuous sharp and snapping clack came from the harden colloids of CFRP in specimen. As load attained peak value followed by descend trend, steel tube began to show clear signs of wall buckling. Local buckling occurred equally on each side of the square tube and become more and more obvious, with higher apparent distortions. Then the load, rebounded back after short dropping, increased in linear relation with longitudinal strain. A sudden loud noise came from inner of the specimen indicated CFRP ruptured, right followed by indicator of testing machine dropped backwards. The bearing capacity of specimen sharply reduced, and specimen failed.

HCFSST-CFRP stub column has a good advantage in mechanical performance compared with normal column after plastic buckling of square steel tube happened. The CFRP tube can improve ductility of normal CFST column remarkably.

The loads $(N)$ versus average axial strain $(\varepsilon)$ curves of HCFSST-CFRP stub column are shown in Figure 3. It indicates that confinement of CFRP tube can improve ductility of normal CFST stub column, and specimen with thicker wall of CFRP tube has better ductility. The rupture bearing capacity (when CFRP start to rupture) of the HCFSST-CFRP stub column under axial compression load will rebound, and the value even exceed ultimate bearing capacity. For instance rupture bearing capacity of specimen of AS64 (thickness of CFRP is $0.668 \mathrm{~mm}$ ) was improved by $22 \%$, and average axial strain attained $28547 \mu \varepsilon$. 


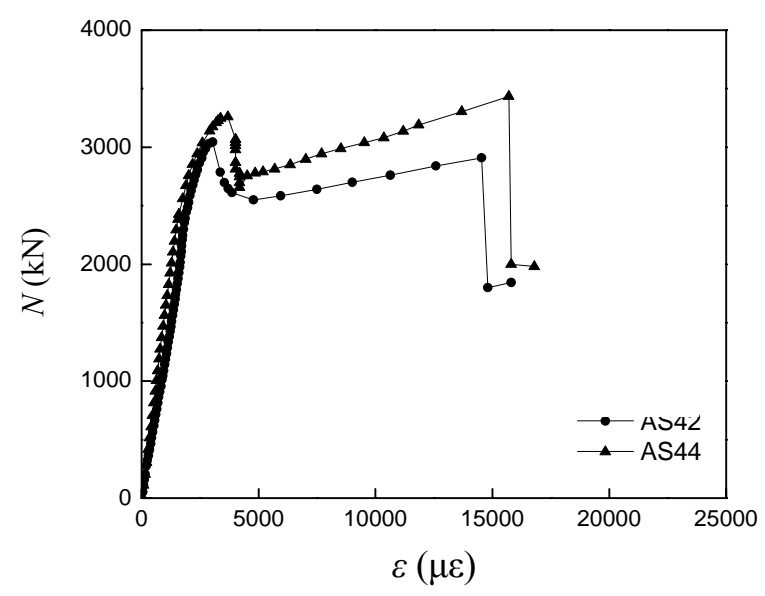

(a)

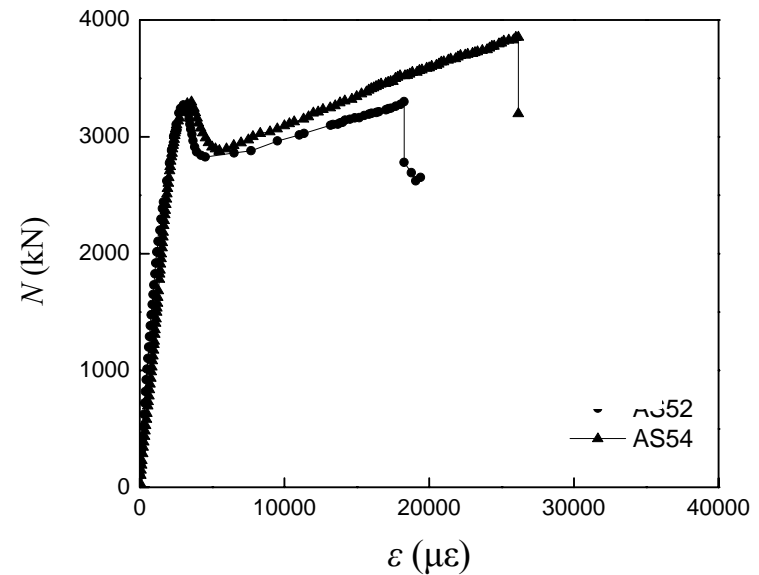

(b)

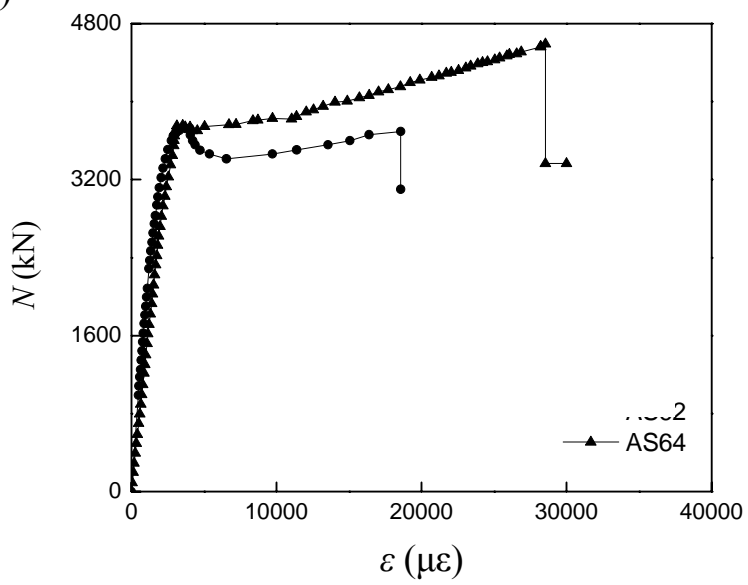

(c)

Figure 3. Experimental Axial Load $(N)$ Versus Average Axial Strain $(\varepsilon)$ Relationship

\subsection{Analysis of Stress Distribution of CFRP}

In the test, longitudinal and transverse strain gauges were pasted on CFRP tube at mid-height of specimen, with interval of 45 degrees. Changes of value of circumferential tangential strain were observed, and stress distribution of middle cross-section of CFRP tube was shown in Figure 4. According to the Figure 4, the changes of circumferential directional strain of CFRP are distributed very well, which means that tension of fiber of CFRP transferred well.

A few strain gauges were broken in processing of assembling specimen. In analysis, strain gauges that work properly were selected. It can be found that most of strain gauges work well and should have been bonding well with CFRP. 


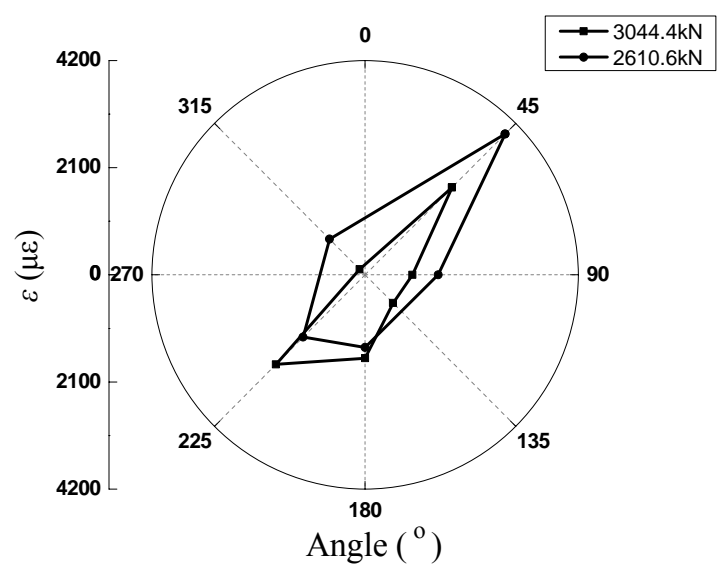

(a) AS42

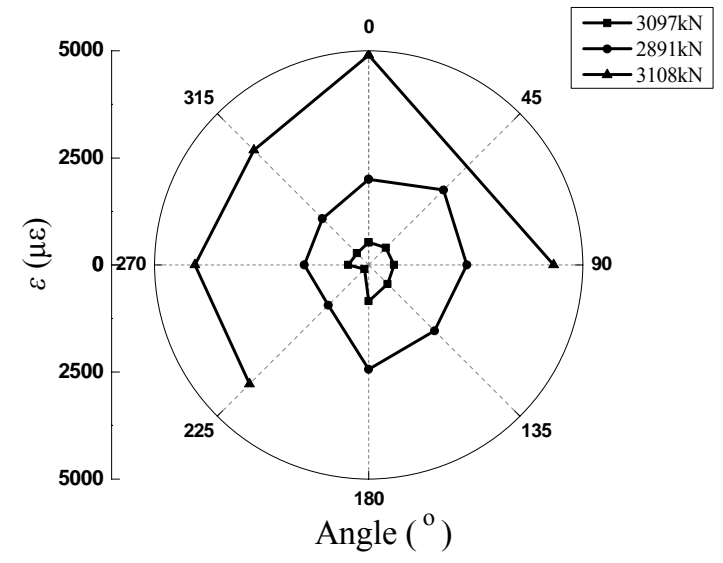

(c) AS52

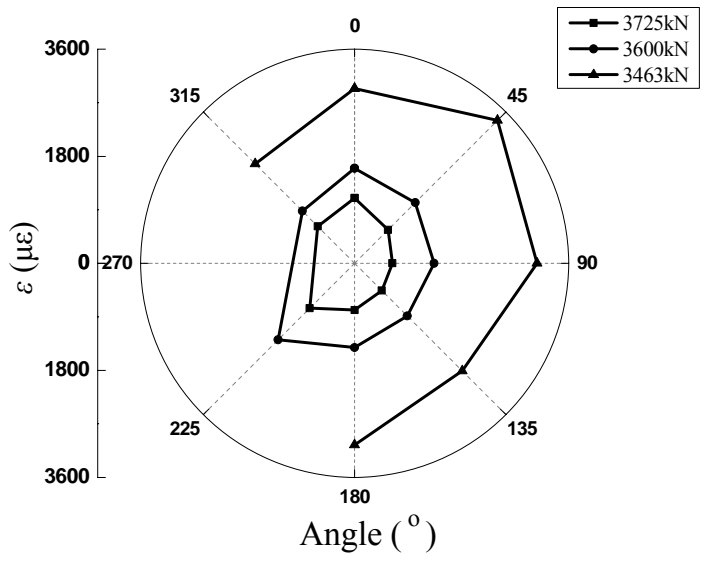

(e) AS62

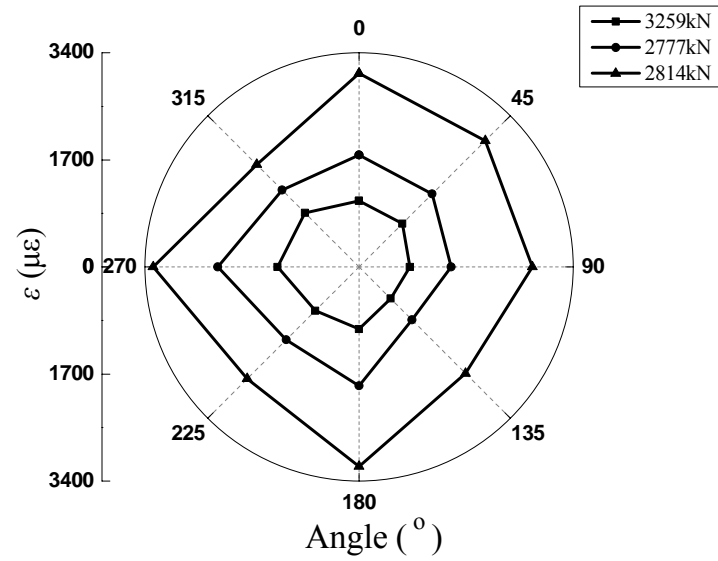

(b) AS44

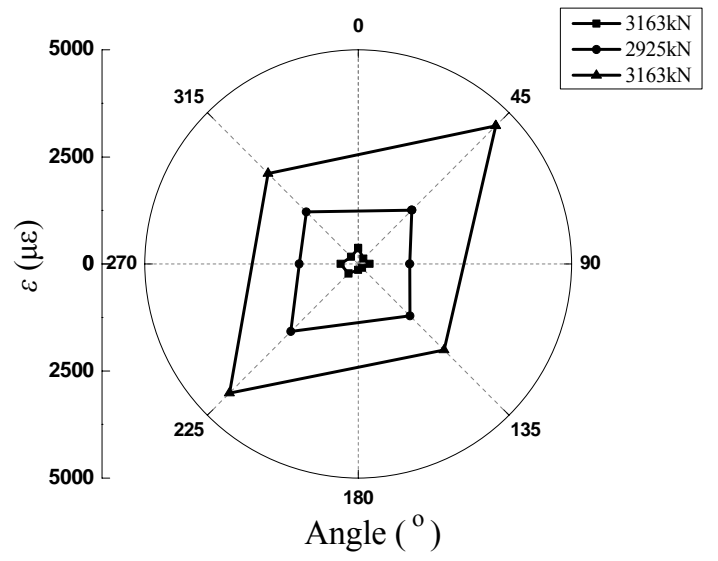

(d) AS54

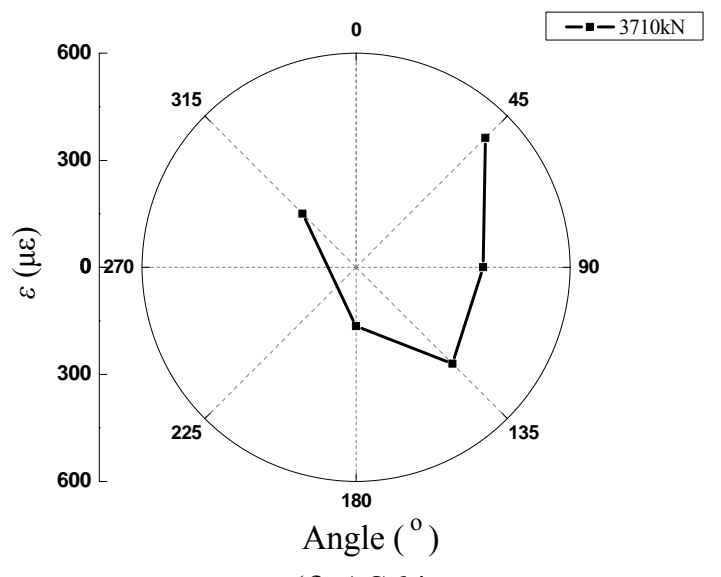

(f) AS64

Figure 4. Stress Distribution of Middle Cross-section of CFRP Tube 


\section{FINITE ELEMENT ANALYSIS}

\subsection{Constitutive Model for Steel}

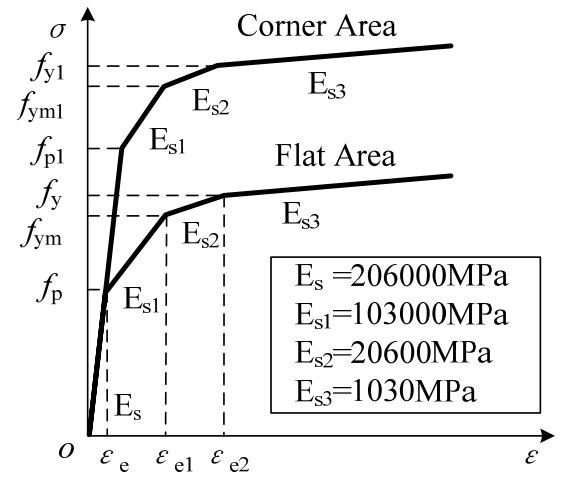

(a) Steel Stress $(\sigma)$ - Strain $(\varepsilon)$ Curves

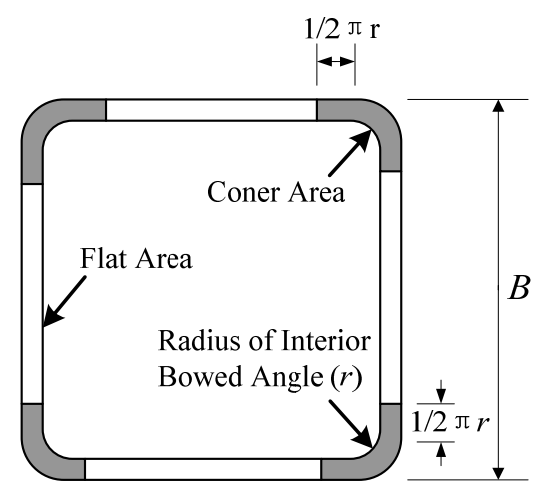

(b) Plate versus Corner Area of Steel Tube

Figure 5. Constitutive Model of Cold-formed Square Steel

Cold-formed steel tube was applied in the test, and steel tube section is divided into two zones: a corner zone and a flat zone, as shown in Figure 5. Abdel-Rahaman and Sivakumaran [16] presented the constitutive equation, which was applied to plate area of square tube, as following Eq. 1 shown.

$\sigma=\left\{\begin{array}{lc}E_{\mathrm{s}} \varepsilon & \left(\varepsilon \leq \varepsilon_{\mathrm{e}}\right) \\ f_{\mathrm{p}}+E_{\mathrm{s} 1}\left(\varepsilon-\varepsilon_{\mathrm{e}}\right) & \left(\varepsilon_{\mathrm{e}} \leq \varepsilon \leq \varepsilon_{\mathrm{e} 1}\right) \\ f_{\mathrm{ym}}+E_{\mathrm{s} 2}\left(\varepsilon-\varepsilon_{\mathrm{e} 1}\right) & \left(\varepsilon_{\mathrm{e} 1} \leq \varepsilon \leq \varepsilon_{\mathrm{e} 2}\right) \\ f_{\mathrm{y}}+E_{\mathrm{s} 3}\left(\varepsilon-\varepsilon_{\mathrm{e} 2}\right) & \left(\varepsilon_{\mathrm{e} 2} \leq \varepsilon\right)\end{array}\right.$

Where $\varepsilon_{\mathrm{e}}=0.75 f_{\mathrm{y}} / E_{\mathrm{s}}, \quad \varepsilon_{\mathrm{e} 1}=\varepsilon_{\mathrm{e}}+0.125 f_{\mathrm{y}} / E_{\mathrm{s} 1}, \quad \varepsilon_{\mathrm{e} 2}=\varepsilon_{\mathrm{e} 1}+0.125 f_{\mathrm{y}} / E_{\mathrm{s} 2}, \quad f_{\mathrm{p}}=0.75 f_{y}$, $f_{\mathrm{ym}}=0.875 f_{\mathrm{y}}$.

According to the study of Karren and Winter [17] and Abdel-Rahman and Sivakumaran [16], following Eq. 2 is applied to calculate yield strength $f_{\mathrm{y}}$ of the corner area of square tube.

$f_{\mathrm{y} 1}=\left[0.6 \frac{B_{\mathrm{c}}}{(r / t)^{\mathrm{m}}}+0.4\right] f_{\mathrm{y}}$

Where $B_{\mathrm{c}}=3.69\left(f_{\mathrm{u}} / f_{y}\right)-0.819\left(f_{\mathrm{u}} / f_{\mathrm{y}}\right)^{2}-1.79, \quad m=0.192\left(f_{\mathrm{u}} / f_{\mathrm{y}}\right)-0.068$ and $f_{\mathrm{u}}$ is ultimate strength of steel. Therefore the format of the Equation (1) was still applied, and $f_{\mathrm{p}} 、 f_{\mathrm{ym}}$ and $f_{\mathrm{y}}$ should be replaced by $f_{\mathrm{p} 1} 、 f_{\mathrm{ym} 1}$ and $f_{\mathrm{y} 1}$.

\subsection{Constitutive Model for Concrete}

The concrete of concrete-filled steel tubular column is under triaxial compression while subjected to axially load. Therefore, the improvement of strength of concrete should be taken into account. Eq. 3 is applied in the paper [18]. 
$y= \begin{cases}2 x-x^{2} & (x \leqslant 1) \\ \frac{x}{\beta_{0}(x-1)^{\eta}+x} & (x>1)\end{cases}$

Where $x=\frac{\varepsilon}{\varepsilon_{0}}, y=\frac{\sigma}{\sigma_{0}}, \sigma_{0}=f_{\mathrm{c}}^{\prime}\left(f_{\mathrm{c}}^{\prime}\right.$ is cylinder compressive strength of concrete, which is expressed as $\left.f_{\mathrm{c}}^{\prime}=f_{\mathrm{cu}}-8\right), \quad \varepsilon_{0}=\varepsilon_{\mathrm{c}}+800 \cdot \xi_{\mathrm{s}}^{0.2} \cdot 10^{-6}, \quad \varepsilon_{\mathrm{c}}=\left(1300+12.5 \cdot f_{\mathrm{c}}^{\prime}\right) \cdot 10^{-6}$.

$\eta=1.6+1.5 / x$, and $\beta_{0}=\frac{\left(f_{\mathrm{c}}^{\prime}\right)^{0.1}}{1.2 \sqrt{1+\xi_{\mathrm{s}}}}$.

\subsection{Constitutive Model for CFRP}

CFRP was considered as linear elasticity material in this paper. When the strain of carbon fiber achieves limited value $\varepsilon_{\mathrm{f}}$, fiber rupture and CFRP lose load bearing capacity. The characteristic is expressed as following equation.

$$
\begin{array}{ll}
\sigma_{\mathrm{f}}=E_{\mathrm{f}} \varepsilon & \varepsilon \leqslant \varepsilon_{\mathrm{f}} \\
\sigma_{\mathrm{f}}=0 & \varepsilon>\varepsilon_{\mathrm{f}}
\end{array}
$$

As Eq. 4 shows, when $\varepsilon=\varepsilon_{\mathrm{f}}$, a value singularity occurs that value of strain change rapidly from limited value of $\varepsilon_{\mathrm{f}}$ to zero. However, for iterative calculation converge more easily, sudden change of value always be avoided. Therefore, the concept of damage was applied to model mechanism of CFRP. When strain of carbon fiber gets close to limited strain $\varepsilon_{f}$, the elastic-plastic characteristic is not obvious, and then CFRP ruptures suddenly. Plastic characteristic was not taken into account, and CFRP was considered as linear elasticity, as shown in Figure 6(a).

Unidirectional CFS along the hoop was used to fabricate the CFRP tube. "1" represents the direction along the fibers, "2" represents the direction perpendicular to the fibers on the plane of CFS and "3" represents the direction perpendicular to the plane of CFS, as shown in Figure 6(b). Lamina [19] model was applied in the finite element analysis (FEA) model of CFRP in elastic stage, and Hashin [19] damage model was applied to model mechanism of CFRP in the stage of rupture.

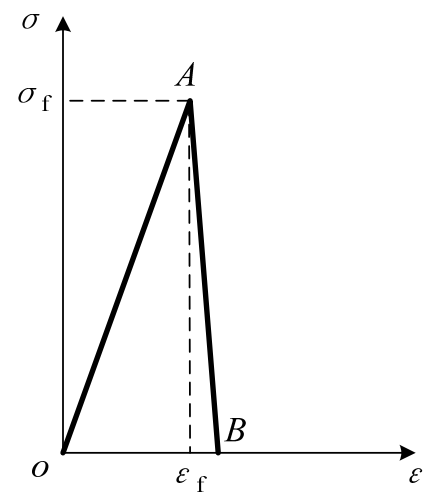

(a) CFRP Stress $(\sigma)$ - Strain $(\varepsilon)$ Curve

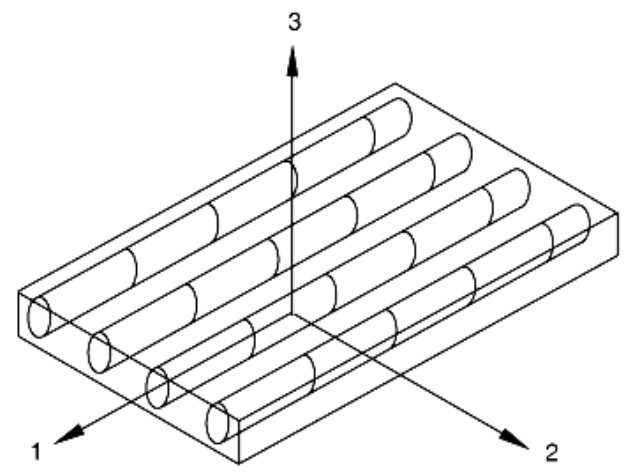

(b) Sketch of Unidirectional Carbon Fiber Sheet (CFS)

Figure 6. CFRP Model 


\subsection{Results Comparison between FEM and Test}

The results between FEM and test were compared. Figure 7 shows the load $(N)$ and longitudinal strain $(\varepsilon)$ curves of FEM and test. The FEM results are in agreement with the test results.

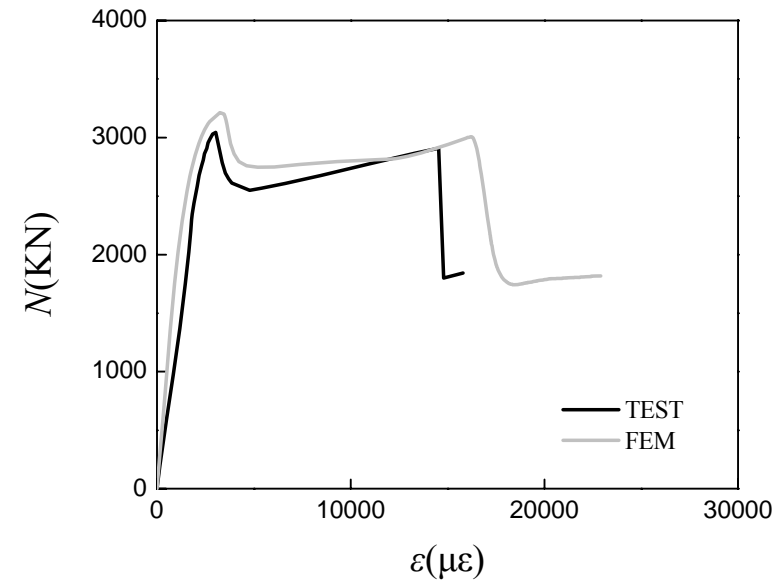

(a) AS42

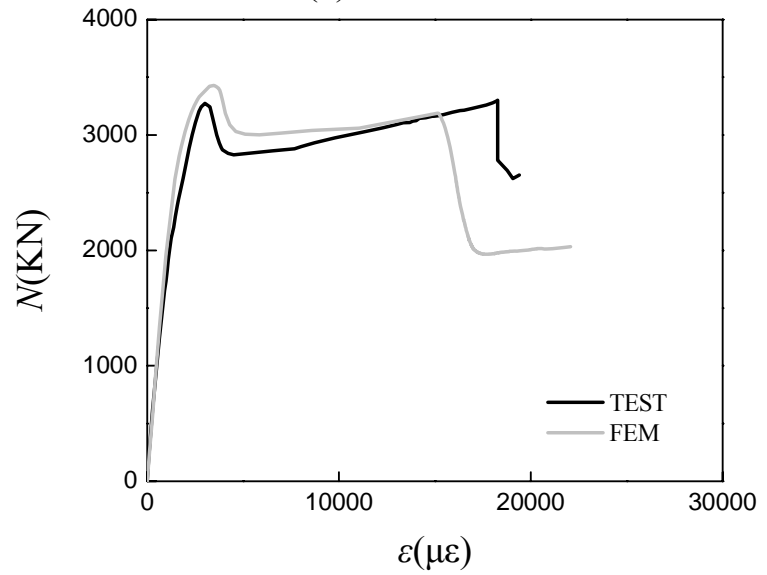

(c) AS52

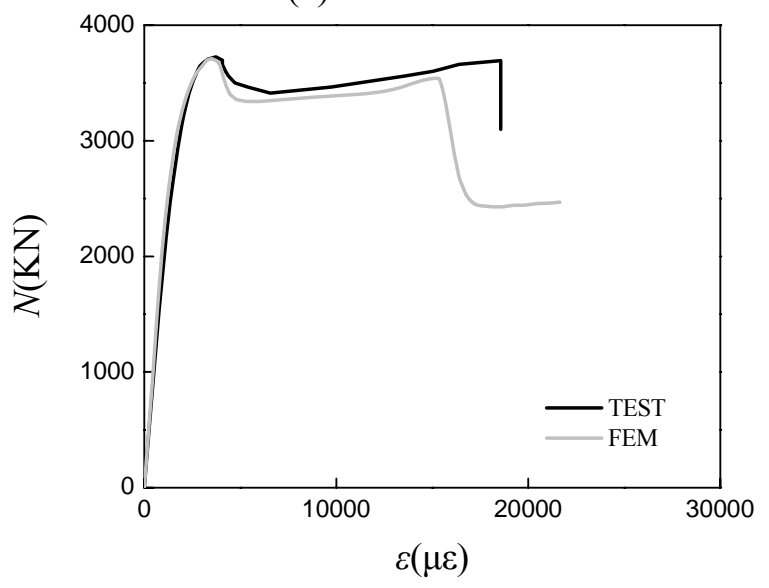

(e) AS62

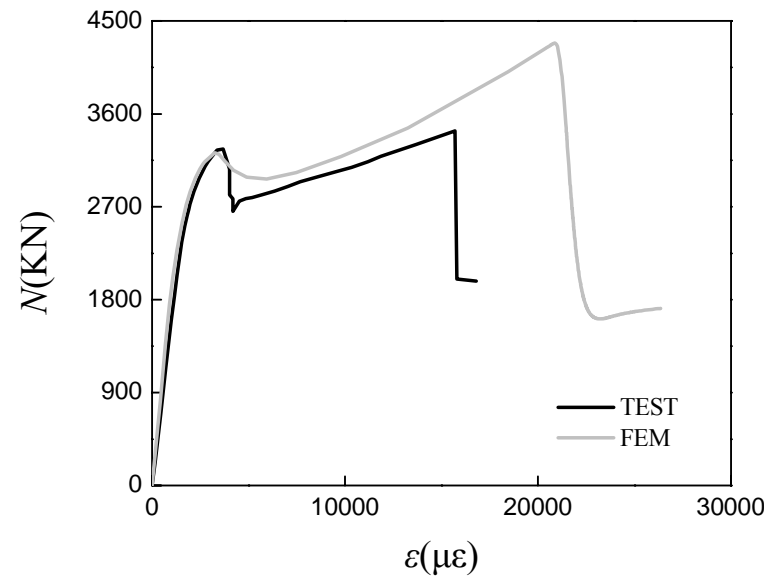

(b) AS44

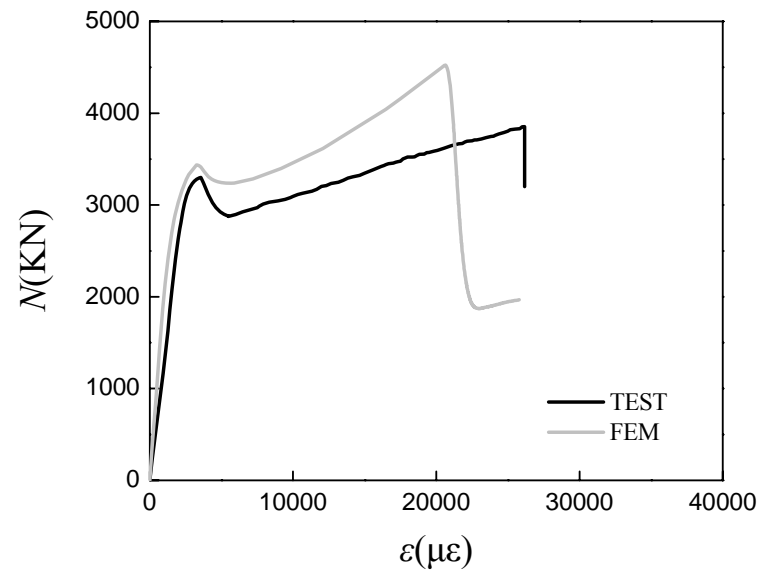

(d) AS54

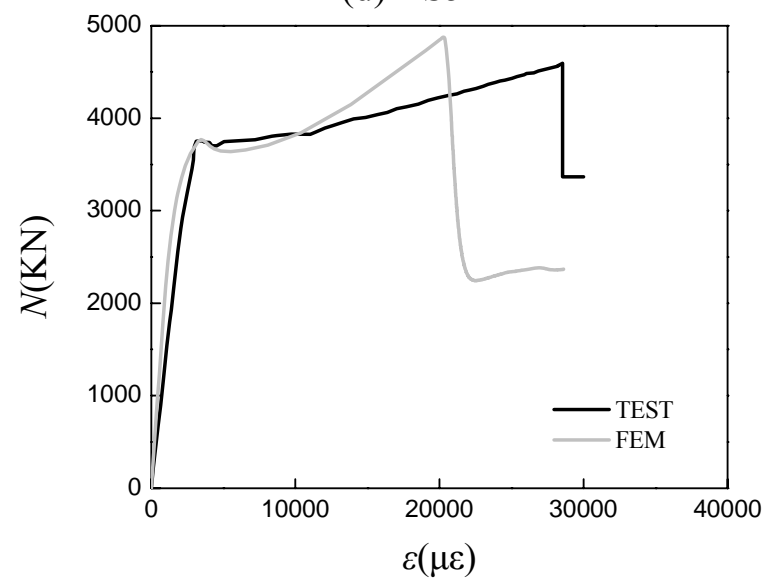

(f) AS64

Figure 7. The Load $(N)$-Longitudinal Strain $(\varepsilon)$ Curves of FEM and Test 


\subsection{Strain Field Analysis of Concrete Core}

As Figure 8 shows, the typical axial load $N$ versus longitudinal strain $\varepsilon$ curve of HCFSST-CFRP stub column includes four line segments, which are first straight line, parabola, second straight line and break line.

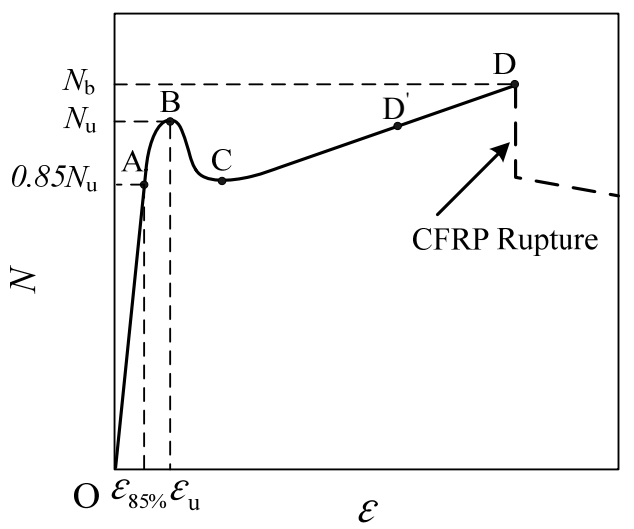

Figure 8. Typical Axial Load $N$ Versus Longitudinal Strain $\varepsilon$ Curve

(1) Elastic stage (OA): During this stage, steel tube and concrete core work alone, there is no obvious interaction among them. Tangential tension of CFRP is small. Point A represents the end of elastic stage, and also is the beginning of elastic-plastic stage.

(2) Elastic-plastic stage (AB): During this stage, crack in sandwich concrete keep developing under external load, and Poisson ratio of sandwich concrete begin to dominate steel. Restraint effect of steel tube to concrete core improved greatly. Cracks were found in the innermost concrete, all of the cracks were slight, because innermost concrete is restrained by steel tube and CFRP tube.

(3) Degraded stage (BC): Point B is a first extremum of $N$ and $\varepsilon$ curve. During this stage, load keep falling while longitudinal train increased.

(4) Rebound stage (CD): While longitudinal strain keep increasing, Poison ratio of innermost concrete increase rapidly. Therefore, during this stage, confinement effect of CFRP tube to innermost concrete increases, and the bearing capacity increases. The load rebounds to point $\mathrm{D}$ of the curve, and CFRP tube begins to rupture, load decrease sharply. To avoid conflicting with bearing capacity $N_{\text {ue }}$ (point B ), rupture bearing capacity $N_{\text {be }}$ (point D) was defined. And, point $\mathrm{D}^{\prime}$ was also defined in order to avoid singularity of point $\mathrm{D}$ for FEM analysis.

Figure 9 shows the longitudinal concrete stress distribution of AS52 at characteristic point A, B, C, and $\mathrm{D}^{\prime}$ in Figure 8. It can be seen that concrete stress distribution is in elastic range, when load is small (according to point A). When specimen attains ultimate load (according to point B), Poisson ratio of concrete exceed steel due to the plastic deformation of concrete. As load continue to decrease to point $\mathrm{C}$, discontinuity of sandwich concrete and innermost concrete is obvious. Concrete features are: longitudinal stress distribution is not even and discontinuous, like phenomenon fault in geotechnical engineering. As load rebound to near point $\mathrm{D}^{\prime}$, discontinuity becomes more serious and stress of innermost concrete is larger. 


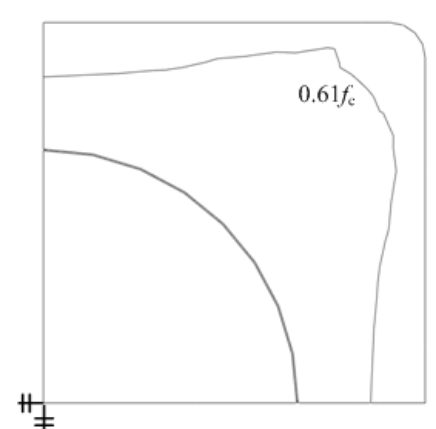

A

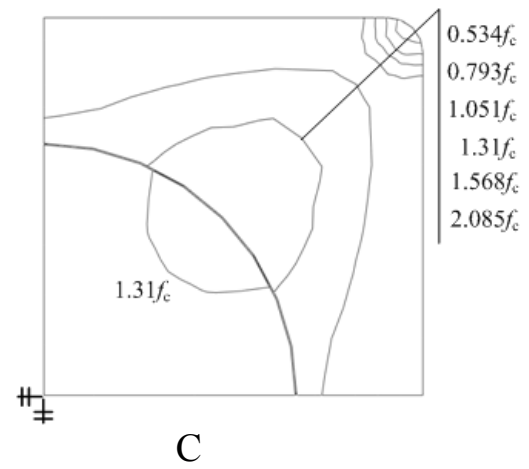

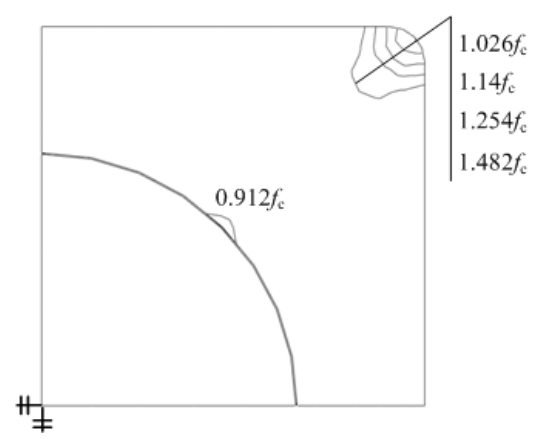

B

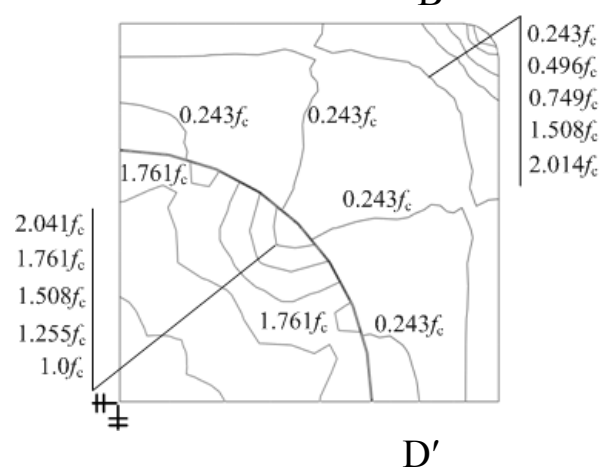

Figure 9. Longitudinal Concrete Stress Distribution of HCFSST-CFRP of A S52

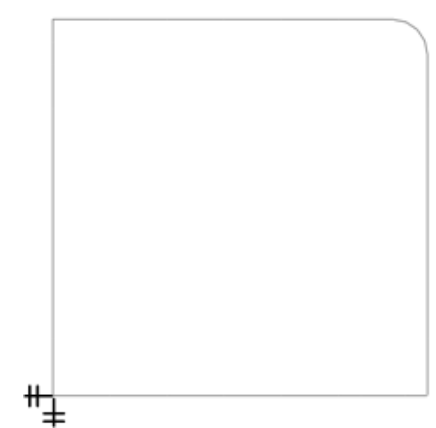

A

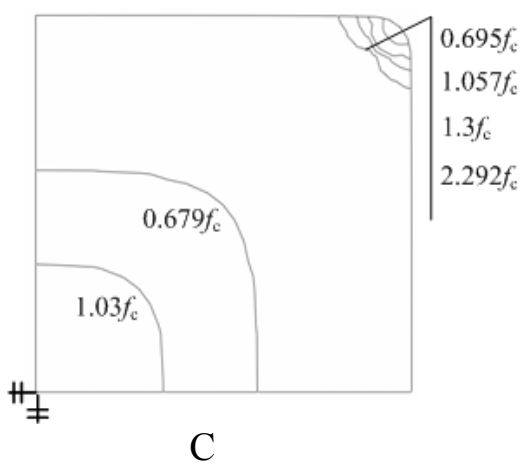

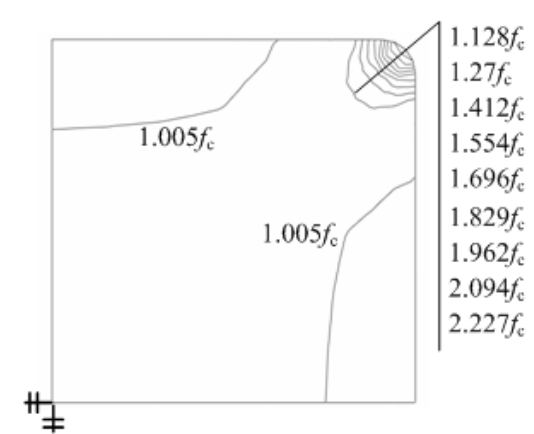

B

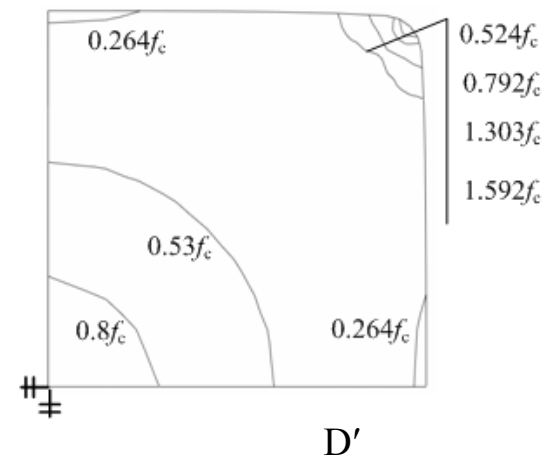

Figure 10. Longitudinal Concrete Stress Distribution of CFST of AS50

The longitudinal concrete stress distribution of CFST is shown in Figure 10. The longitudinal concrete stress distribution of CFST is relatively small, corresponding to point $\mathrm{C}$ on the $N$ and $\varepsilon$ curve. Because the confinement of concrete core subjected to steel tube is small after point $\mathrm{C}$, longitudinal concrete stress distribution of CFST seems smaller. 
The analysis results indicate that confinement effect of CFRP tube to innermost concrete mainly begins to work after steel tube buckling. Refinement of CFRP can improve the ductility of CFST remarkably in the beginning of degraded stage.

\subsection{Analysis of Steel Tube}

Because of characteristic of cold-formed steel tube, improvement of stress of the corner was taken into account. Model of steel tube in FEM was divided into corner area and plate area, and was assigned corresponding property. Figure 11 shows that Von Mises stress distribution of steel tube for $1 / 2$ model. When load is small (according to point $C$ of the curve), the value of Von Mises stress is within elastic limit. When load is bigger at point $\mathrm{C}$ of the curve, most part of the steel tube is in the plastic stage.

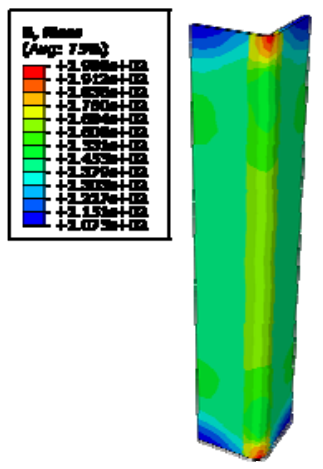

A
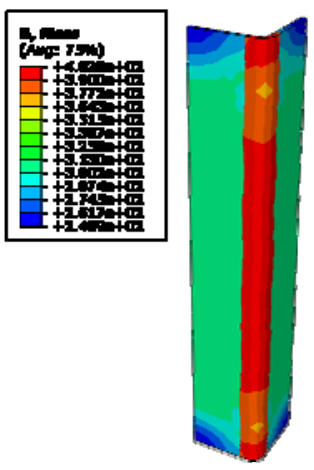

$\mathrm{B}$

Figure 11. Von Mises Stress Distribution of Steel Tube

\subsection{Analysis of CFRP}

Principle vector distributions of CFRP tube are shown in Figure 12, including four figures according to point A, B, C and D. Figure 12 shows that the orientation of principle vector is along tangential of CFRP. Principle stress distributions for CFRP tube are shown in Figure 13. When load is small, according to point A of typical curve, principle vector distributed dispersedly and principle stress was within 104.5 MPa. When load attains limit capacity, according to point B of typical curve, principle stress attains $571.8 \mathrm{MPa}$, equivalent to $1 / 7$ of limit value. According to point $\mathrm{C}$ of the typical curve, principle vector gathers in the middle area of CFST tube and maximum principle stress exceeds 1000MPa. With loading, maximum principle stress keeps increasing and stress distribute evenly in the whole area of CFRP tube.

It is plastic stage when CFRP starts to affect the ductility of specimen and works significantly around point $\mathrm{C}$ of typical curve. And when steel tube is in elasto-plastic stage, the hoop-tangential stress of CFRP is small. 


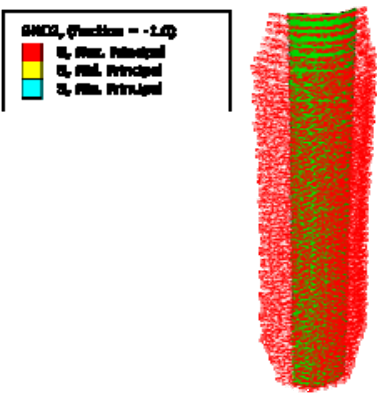

A

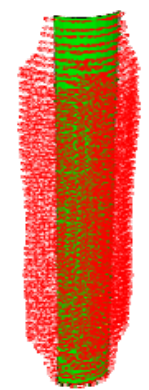

B

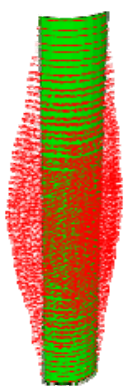

$\mathrm{C}$

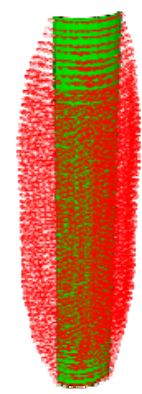

$\mathrm{D}^{\prime}$

Figure 12. Principle Vector Distribution of CFRP for $1 / 2$ Model

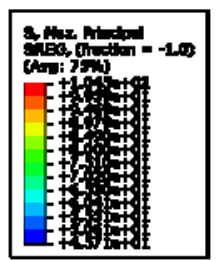

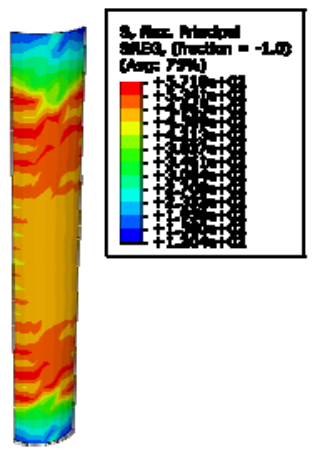

A

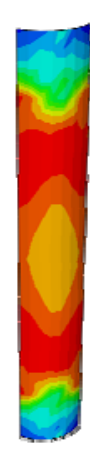

$\mathrm{B}$
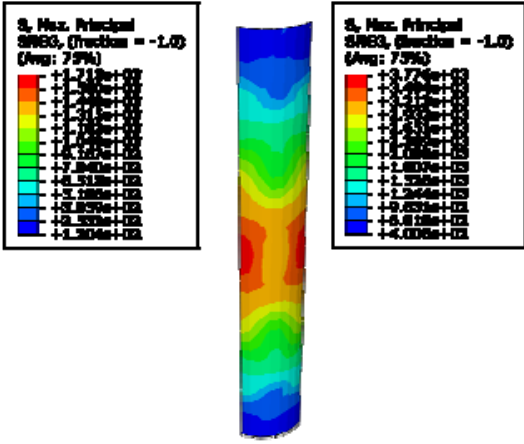

$\mathrm{C}$

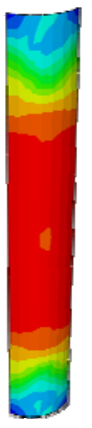

$\mathrm{D}^{\prime}$

Figure 13. Maximum Principle Stress Distribution of CFRP for 1/2 Model

\section{Analysis of Interactions among Steel, Concrete and CFRP}

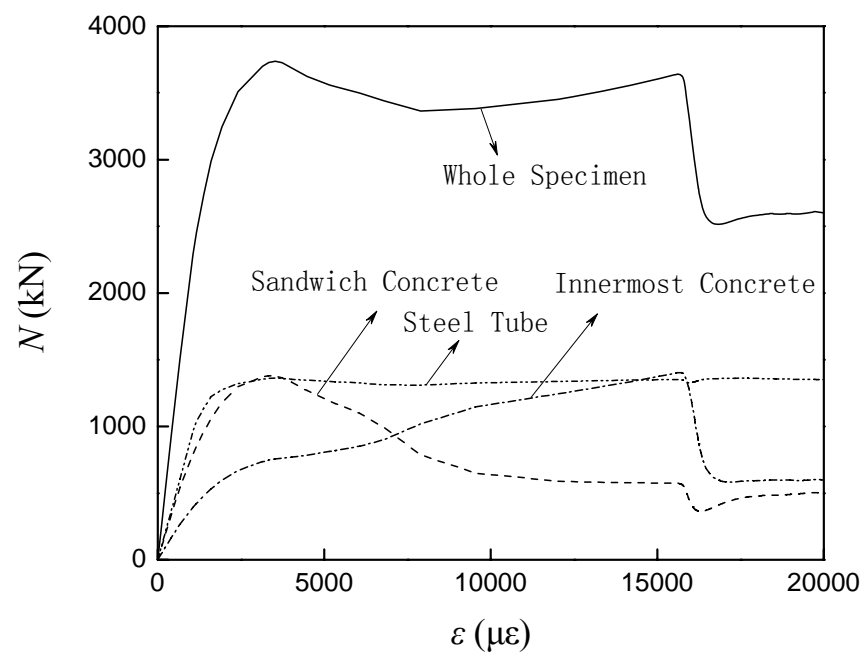

Figure 14. Load versus Longitudinal Stress Curve

Load $(N)$ versus stress $(\varepsilon)$ curve is shown in Figure 14. The load versus stress curve of steel shows that steel enters plastic stage after limit point. The load versus stress curve of sandwich concrete shows that the load shared by sandwich concrete decreases after peak of the curve. The load versus stress curve of innermost concrete shows that the load shared by innermost concrete increases after short plastic flow following peak of curve. 


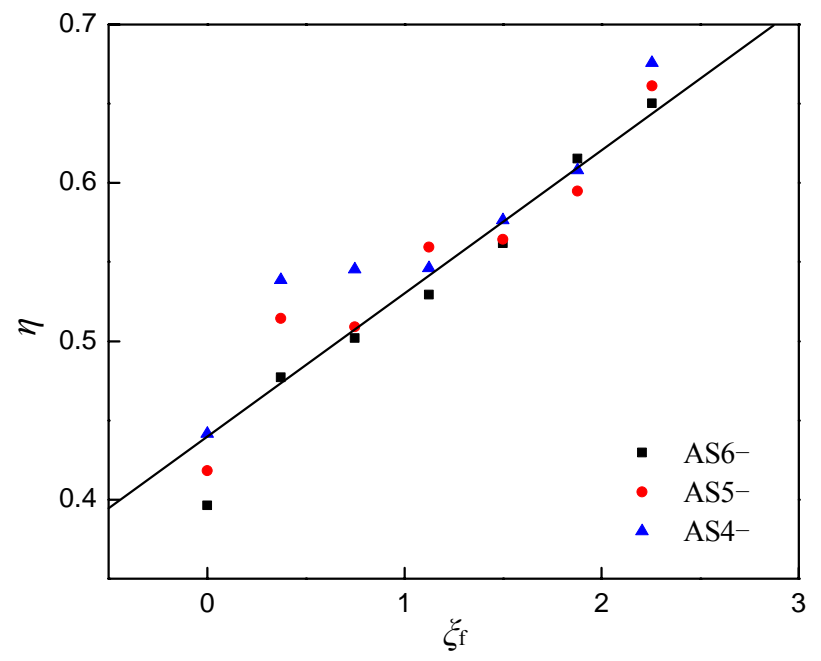

Figure 15. Load Shared Coefficient $(\eta)$ - constraining Factor $\left(\xi_{\mathrm{f}}\right)$ when Load got Bearing Capacity

Based on the validity and reasonability of FEM, more finite element model was made to be calculated. Load shared coefficient $(\eta)$-constraining factor $\left(\xi_{\mathrm{f}}\right)$ at load achieved bearing capacity data distribution, as shown in Figure 15. Where $\eta$ is the ratio of load shared by innermost concrete and sandwich concrete which is expressed as $\eta=N_{\text {id }} / N_{\text {sc }}$. Where $N_{\text {sc }}$ is load shared by sandwich concrete and $N_{\text {ic }}$ is load shared by innermost concrete. Considering $\eta$ is linear correlated with $\xi_{\mathrm{f}}$, linear regression method is applied to deal with the distribution of data. The results of regression method show that load shared by innermost concrete $\left(N_{\mathrm{ic}}\right)$ increases with increase of restraining factor $\left(\xi_{\mathrm{f}}\right)$ of CFRP, as shown in the Eq. 5.

$\eta=0.09 \xi_{\mathrm{f}}+\mathrm{a}$

Where: $\mathrm{a}=0.367+0.15 \xi_{\mathrm{s}}$

Load shared by sandwich concrete $N_{\text {sc }}$ and load shared by innermost concrete $N_{\text {ic }}$ relations can be established based on the following assumptions: (1) CFRP can not work under pressure and longitudinal load is totally shared by concrete core and steel tube. (2) Strengthening of steel is neglected after specimen attain limit capacity. According to assumptions, Load shared by sandwich concrete $N_{\text {sc }}$ and load shared by innermost concrete $N_{\text {ic }}$ of the member can be expressed as:

$$
\begin{aligned}
& N_{\text {sc }}=\frac{1}{0.09 \xi_{\mathrm{f}}+\mathrm{a}}\left(N_{\mathrm{u}}-A_{\mathrm{s}} f_{\mathrm{ya}}\right) \\
& N_{\text {ic }}=N_{\mathrm{u}}-N_{\mathrm{sc}}
\end{aligned}
$$

Where $f_{y a}$ is the weighted mean value of cross-section of cold-formed steel square tube can be calculated by $f_{\mathrm{ya}}=C f_{\mathrm{y} 1}+(1-C) f_{\mathrm{y}}, C$ is ratio of area of cross-section of corner and whole cross-section; $f_{\mathrm{y} 1}$ is yield stress of steel of corner; $N_{\mathrm{u}}$ is bearing capacity; $A_{\mathrm{s}}$ is area of whole cross-section. 


\section{CONCLUSIONS}

(1) CFRP tube can improve the ductility and bearing capacity of CFST column under axial compression. HCFSST-CFRP stub columns totally failed with CFRP rupture.

(2) CFRP tube begins to work obviously at the descent stage after stub column attained ultimate bearing capacity. Namely confinement effect of CFRP tube to innermost concrete mainly begins to work after steel tube buckled

(3) Longitudinal stress distribution of innermost concrete and sandwich concrete is discontinuous, and innermost concrete under confinement of CFRP suffers most of axial load.

(4) CFRP tube works well in the concrete of HCFSST-CFRP stub column. That means tension of circumferential directional fiber of CFRP transferred well.

(5) This paper presents a calculating formula to analyze the load shared by innermost concrete and sandwich concrete. And the experimental work in this paper lays a good foundation for further research on HCFSST-CFRP column.

\section{ACKNOWLEDGEMENTS}

This project was supported by National Science Foundation of China (50678106), Shenyang Talent Development Fund (2009140403038), Liaoning BaiQianWan Talents Program (2009921095), Technology Program of Ministry of Housing and Urban-Rural Development (2011-k3-23).

\section{REFERENCES}

[1] Schneider, S.P., “Axially Loaded Concrete-filled Steel Tubes”, Journal of Structural Engineering, ASCE, 1998, Vol. 124, No. 10, pp. 1125-1138.

[2] Han, L.H., "Tests on Stub Columns of Concrete-filled RHS Sections". Journal of Constructional Steel Research, 2002, Vol. 58, No. 3, pp. 353-372.

[3] Bridge, R.Q., "Concrete Filled Steel Tubular Columns", Rep. No. R283, School of Civil Engineering, University of Sydney, Sydney, Australia, 1976.

[4] Furlong, R.W., "Columns Rules of ACI, SSLC, and LRFD Compared", Journal of the Structural Division ASCE, 1983, Vol. 109, No. 10, pp. 23752386.

[5] Shakir-Khalil, H. and Zeghiche, J., "Experimental Behavior of Concrete Filled Rolled Rectangular Hollow Section Columns", The Structural Engineering, 1989, Vol. 67, No. 19, pp. $346^{-353 .}$

[6] Zhong, S.T., "The Comparison of Behaviors and Economics for Concrete-filled Steel Tube (CFST) with Circular and Square Cross-sections". Journal of Harbin Institute of Technology, 2003, Vol. 35, No. 8, pp. 27.

[7] Forbes, D., "Three Tall Buildings in Southern China", Structural Engineering International, 1997, Vol. 7, No. 3, pp. 157-159.

[8] Mc Graw-Hill, "Structural System for Tall Buildings", Council on Tall Buildings and Urban Habitat, New York, 1995.

[9] Han, L.H., "Some Recent Applications and Researches in Concrete-filled Steel Tubular Structures", Siencepaper Online, Beijing, 2005. 
[10] Hsuan, T.H., Huang, C.S., Wu, M.H. and Wu, Y.M., "Nonlinear Analysis of Axially Loaded Concrete-Filled Tube Columns with Confinement Effect", Journal of Structural Engineering, ASCE, 2003, Vol. 129, No. 10, pp. 1323.

[11] Cai, J. and He, Z.Q., "Eccentric-loaded Behavior of Square CFT Columns with Binding Bars", Journal of Building Structures, 2007, Vol. 28, No. 4, pp. 25-35.

[12] Wang, Z.H. and Cheng, R., "Axial Bearing Capacity of Composite-sectioned Square Concrete-filled Steel Tubes", Journal of Tsinghua University (Science and Technology), 2005, Vol. 12, pp. 1596-1597.

[13] Lu, T.Q. and Zhao, G..F., "Numerical Method for Analysis of Ultimate Strength of Concrete-filled Square Steel Tubular Columns Under Eccentric Compression Reinforced by Inner Circular Steel Tube", Journal of Dalian University of Technology, 2001, Vol. 41, No. 5 , pp. 612.

[14] Tao, Z. and Zhuang, J.P., "Mechanical Behavior of Stub Columns of FRP-confined Concrete-filled Steel Tubes", Industrial Construction, 2005, Vol. 35, pp. 9.

[15] Yu, Z.W. and Ding, F.X., "Unified Calculation Method of Compressive Mechanical Properties of Concrete", Journal of Building Structures, 2003, Vol. 24, No. 5.

[16] Abdel-Rabman, N., "Sivakumaran K.S. Material Properties Models For Analysis of Cold-Formed Steel Members", Journal of Structural Engineering, 1997, Vol. 123, No. 9, pp. 113-1143.

[17] Karren, K.W. and Winter, G.., "Effects of Cold-Forming on Light-Gauge Steel Members", Journal of the Structural Division, ASCE, 1967, Vol. 93, No. 1, pp. 433-469.

[18] Liu, W., "Research on Mechanism of Concrete-Filled Steel Tubes Subjected to Local Compression”, Fuzhou: Fuzhou University, 2005.

[19] ABAQUS Theory Manual, ABAQUS Analysis User's Manual. 